\title{
Blucher
}

\author{
Blucher Proceedings \\ Cuba e Brasil no Século XXI (CBS21) \\ A Construção do Conhecimento
}

\section{Fundação Joaquim Nabuco, perspectivas de parcerias entre Cuba e Brasil}

Fernando Freire ${ }^{1}$

Preconizada no Congresso Nacional, criada por vontade parlamentar, a Fundação Joaquim Nabuco despontou no cenário brasileiro em 1949, pelo esforço e iniciativa do então deputado federal constituinte Gilberto Freyre, que defendeu na tribuna a criação de um centro de estudos sociais no Nordeste brasileiro.

O autor de Casa-grande \& senzala manifestou o desejo de realizar uma espécie de inquérito científico sobre as condições de vida do trabalhador rural, pretendendo dar base regional aos estudos sobre o homem brasileiro.

Assim se ergueu na cidade do Recife, após plenárias acirradas, o Instituto Joaquim Nabuco, instituição dedicada ao estudo sociológico das condições de vida do trabalhador brasileiro da região agrária do Nordeste do país nos seus amplos aspectos: sociais, econômicos e culturais. O IJN - denominado Instituto Joaquim Nabuco de Pesquisas Sociais - IJNPS na década de 60 - foi constituído, originariamente, como órgão administrativo do Ministério da Educação e Saúde.

Em rápida retrospectiva, a primeira pesquisa realizada pela Instituição contou com o apoio da Organização das Nações Unidas - ONU. Em 1951, tratou-se de estudar o problema da habitação rural nos Estados de Alagoas, Pernambuco, Paraíba, Rio Grande do Norte e Ceará, e apresentar sugestões para melhorá-la, por meio do emprego de materiais locais e de um melhor desempenho das construções, considerando inclusive fatores relacionados às condições de saúde. A segunda resultou de acordo com a Organização das Nações Unidas para a Educação a Ciência e a Cultura - UNESCO em que se propôs um plano de pesquisa sobre as relações raciais no Brasil.

Com o mesmo propósito, seguiram-se outras igualmente pioneiras sobre o Padrão de Vida das Famílias Brasileiras; Mortalidade e Longevidade em municípios da

\footnotetext{
${ }^{1}$ Fundação Joaquim Nabuco (FUNDAJ), Recife, PE, Brasil. E-mail: fernando.freire@fundaj.gov.br.
} 
Mata, Agreste e Sertão de Pernambuco; e Estatísticas do Ensino Primário no Nordeste Oriental, para citar apenas algumas desse período inicial, também responsável por sediar o intercâmbio de bolsistas nacionais e estrangeiros, que aqui vieram estudar a realidade nordestina, com o objetivo de elaborar teses em nível de pós-graduação, e no Instituto encontraram um centro de pesquisas científicas preparado para a orientação de trabalhos acadêmicos, exercendo função complementar às universidades.

Nesse recorte, em 1980, o Instituto passa a ser Fundação, amplia a sua área de atuação, abrangendo também a região Norte do Brasil, e apresenta dentre outros objetivos gerais:

- Promover a execução de estudos, pesquisas, planos e projetos destinados à compreensão da realidade sócio-econômica e cultural das regiões que constituem sua área de atuação, com vista à melhoria das condições de vida do homem brasileiro, especialmente do trabalhador rural, difundindo os seus resultados;

- Preservar os valores históricos culturais promovendo a documentação em suas múltiplas formas, inclusive a museologia, pesquisando, estimulando e difundindo manifestações culturais regionais;

- Dispensar, no seu campo de atividades e sempre que possível, assistência educacional gratuita a estudantes carentes.

Nos anos de 1990, a Fundação elege sete áreas temáticas para desenvolver as suas atividades: Cultura e Identidade; Pensamento Social no Brasil; Estado, Cidadania e Atores Sociais; Gênero, Família e Idade; Desenvolvimento Regional e Urbano e Políticas Públicas; População e Exclusão Social; Sociedade, Agricultura e Meio Ambiente.

A partir de 2003, inicia-se um processo de maior aprofundamento do vínculo institucional da Fundação com o Ministério da Educação, por força do desafio que a população brasileira impôs ao Governo Federal de promover profundas mudanças no modelo de desenvolvimento em vigor, que passaram a exigir educação de qualidade para todos os brasileiros, urgência na redução da pobreza e das desigualdades sociais, redução dos desequilíbrios regionais, maior distribuição de renda, melhores oportunidades de trabalho, e ambiente com sustentabilidade.

A Fundação Joaquim Nabuco reafirma o seu compromisso de contribuir para a construção de novos e duradouros caminhos, que conduzam, sobretudo, ao desenvolvimento sustentável da Região Nordeste do país, buscando integrá-la ao contexto nacional. A Fundação se insere no processo de formulação e execução de políticas públicas voltadas ao pleno exercício da cidadania, no sentido mais abrangente, mediante ações de pesquisa, de formação de pessoal, cultura e preservação 
do patrimônio histórico material e imaterial. Tendo, portanto, a missão de produzir, acumular, difundir e ensinar conhecimentos; pesquisar, preservar e difundir a memória coletiva da sociedade brasileira; promover atividades científicas, culturais e educativas, perseguindo o avanço da sociedade brasileira nas conquistas sociais, educacionais, políticas e econômicas.

Para tanto, expôs os seguintes objetivos a serem perseguidos:

- Comprometer-se com a mudança processada no País e com os objetivos do Ministério da Educação - MEC;

- Promover a inclusão social e servir à sociedade, tornando-se aliada ao esforço de desenvolvimento nacional integrado;

- Subsidiar a formulação de políticas públicas;

- Organizar sistema de informações e disponibilizar o acervo, favorecendo a democratização do conhecimento.

Com isso a Fundação apresentou ao MEC um histórico da Instituição e exibiu os significativos avanços alcançados, apontando também as dificuldades enfrentadas e os desafios continuados no sentido de construir um modelo de atuação voltado para qualificar um processo decisório, que assegurasse a sintonia com o Programa do Governo Federal; ampliasse a regionalização das ações num raio interestadual; intensificasse os projetos e as ações educacionais, atendendo às necessidades do Ministério; desenvolvesse estudos e pesquisas sobre a realidade do Nordeste, com ênfase no desenvolvimento sustentável e na inclusão social nas diversas áreas; alargasse os laços com a sociedade civil e o conjunto da população, aprofundasse os estudos sobre o pensamento de Joaquim Nabuco, relacionados aos problemas da atualidade.

Alguns desses desafios foram alcançados, outros não lograram o êxito na proporção desejada, naquilo que se deixou de visualizar, em estrita compreensão, o pretendido alinhamento com o MEC.

A partir de abril de 2011, a Fundação Joaquim Nabuco é convocada a se inserir no Plano Nacional de Educação, focando a maior parte de suas ações no desenvolvimento do plano nacional e colaborando efetivamente para um país com mais educação, inclusivo e preocupado com a sustentabilidade do ambiente, principalmente no Nordeste, onde se tem aplicado nos últimos anos um volume significativo de recursos para o desenvolvimento de projetos de grande porte, de largo impacto social e cultural na vida dos nordestinos. Região que ainda detém um dos mais baixos índices de escolaridade e de aprendizado do País, posição a exigir comprometimento de todos os brasileiros na luta por universalidade, eficiência e qualidade, em todos os elos da cadeia educacional. 
Para esse novo momento institucional, a Fundação Joaquim Nabuco reúne toda energia para consolidar sua luz de conhecimento e exacerbar sua capacidade potencial de pesquisar, educar e compreender o ambiente, com servidores envolvidos nos grandes temas do Nordeste, interiorizando as suas ações, tendo a participação social como protagonista e, com tal esforço concentrado, contribuir para o desenvolvimento do País.

Nesse seu novo momento a Fundação Joaquim Nabuco definiu sua missão institucional de forma a atuar nos campos da educação e cultura de forma interdependente, visando o crescimento justo e sustentável da sociedade brasileira.

Para dar conta deste ousado dueto de educação e cultura, a Fundação Joaquim Nabuco pretende ampliar suas parcerias internacionais. Como dizia o ex-ministro Fernando Haddad e atualmente prefeito da cidade de São Paulo:

"As parcerias deverão ser baseadas nas demandas dos países pobres, a partir das estratégias nacionais de desenvolvimento e não baseadas na oferta de países ricos".

Assim, elaborou-se uma proposta de apresentar um plano de inserção internacional da instituição, em cumprimento a uma das diretrizes da gestão de iniciar e consolidar uma cooperação internacional que possibilite a Fundação "inserir-se no mundo em parcerias voltadas ao estudo do Homem do Nordeste". Essa diretriz está afinada com Ministério da Educação, que defende o fortalecimento da cooperação internacional em favor da educação, apoiada no oitavo objetivo do milênio, a parceria global para o desenvolvimento.

Com isso foi possível elaborar um documento estruturado em cinco tópicos:

1. Diagnóstico;

2. Identificação das diretrizes, prioridades e articulações do Governo Federal e do Ministério da Educação, em particular, no campo das relações internacionais;

3. Levantamento das agências de cooperação, fundações, universidades e outras instituições internacionais, por campo de atuação;

4. Proposta de plano de consolidação da Fundação Joaquim Nabuco no mundo, a partir de uma ação articulada no território indicado como prioritário na política internacional do Governo Federal e que leve em conta as expertises da instituição e seu Plano de Ação. A proposta procura ser flexível prevendo a ampliação, formalização e implantação de atividades durante seu desenvolvimento;

5. Recomendações para implementação do Plano de Cooperação Internacional. 
O diagnóstico da situação atual foi realizado com base no levantamento dos acordos formais vigentes na instituição, no exame dos documentos e espaços oficiais disponíveis (site, intranet, relatório de atividades 2007-2010, relatório de gestão e banco de dados das unidades administrativas da Fundação) e mediante entrevistas com diretores, assessores, técnicos e pesquisadores da instituição.

Do levantamento feito nas fontes citadas, foram localizados poucos documentos, uma parcela com seus prazos de vigência encerrados (alguns com possibilidades de retomada) e outros em fase de negociação. Os instrumentos legais seguem as articulações, sendo de escopo reduzido e curta duração, em sua maioria, não havendo registros de acordos de cooperação mais abrangentes.

As entrevistas revelaram um cenário em que as articulações não redundaram em parcerias institucionais. Na maioria delas, evidenciou-se ser significativa a parcela das negociações restritas à participação individual dos servidores em eventos ou em projetos que geraram poucos resultados para a Fundação, o MEC e o Governo Feeral. Outro conjunto de articulações realizadas foi arquivado por falta de apoio institucional.

Concomitante com a situação acima constatou-se a existência de "ações institucionais informais", desenvolvidas diretamente pela Fundação ou intermediadas por parceiros nacionais. Essa foi uma prática usual na Diretoria de Cultura, para realização de exposição, formação nos campos das artes visuais e do audiovisual, além da organização de programa regular de debates sobre pensamento contemporâneo, para citar alguns exemplos.

A explicação unânime para precariedade da inserção internacional da instituição foram as dificuldades encontradas para institucionalizar as articulações feitas, sendo atribuídas a isso a falta de condições políticas, administrativas e jurídicas. A despeito desse cenário, obtive-se desses colaboradores uma relação de instituições que manifestaram interesse em estabelecer parcerias com a Fundação Joaquim Nabuco no desenvolvimento de projetos de pesquisa, em investimentos em formação e intercâmbio de estudantes, técnicos e pesquisadores, na realização de eventos e mesmo na criação de núcleos de pesquisa e estudo.

Para além desse diagnóstico que demonstra pouca internacionalização da Fundação, a proposta agora objetiva atender a diretriz de implementar e consolidar uma política de cooperação internacional, a partir de parcerias que amplie a participação institucional nos debates mundiais e coloque a sua produção científica e cultural no cenário internacional.

Para cumprir esse objetivo, é preciso definir os temas para a cooperação, com base no Planejamento Estratégico da Fundaj, hierarquizá-los de acordo com as prioridades institucionais e pactuá-los com o corpo de técnicos e pesquisadores. É recomendável sua articulação com as diretrizes do Plano Nacional de Educação (PNE), do Plano Nacional de Desenvolvimento da Educação (PNDE), do Plano 
Nacional de Cultura (PNC) e da Política Nacional de Educação Ambiental, além do alinhamento com a política externa do Governo Federal, demarcada por visível preferência pela cooperação sul-sul.

Igualmente é essencial considerar na proposta a complexidade da instituição, o conhecimento produzido e acumulado sobre a região Nordeste onde atua, o seu acervo, a diversidade de seus campos de atuação (educação, meio ambiente, ciências sociais, economia e cultura) e a sua missão estatutária voltada para o desenvolvimento regional do Nordeste brasileiro.

Independente dos temas eleitos, é fundamental que os programas de cooperação contemplem as demandas recíprocas, sejam construídos com base nas experiências e estejam ancoradas nas estruturas organizacionais da Fundaj e dos países envolvidos.

A cooperação sul-sul possibilitará a troca de experiências entre países cujas realidades são muito próximas. Para a Fundaj, o foco nesse recorte se apresenta como uma oportunidade da instituição consolidar, disponibilizar e difundir o conhecimento acumulado ao longo de sua existência, debruçada sobre os universos social, econômico e político do Nordeste brasileiro. A concretização do plano dependerá da capacidade institucional de agregar parceiros estratégicos nacionais e internacionais. Dentre os nacionais são recomendáveis, além dos Ministérios da Educação e das Relações Exteriores, os Ministérios do Meio Ambiente, da Cultura, da Ciência e Tecnologia e do Planejamento (ENAP e IPEA), assim como as Secretarias de Cultura e Educação do Nordeste. No campo internacional, são fundamentais as articulações com a UNESCO, o CERLALC, o PNUD, o CLACSO, a SEGIB, a OEA, Fundações Ford e Fulbright, a Universidade de Stanford, Universidade Lusófona-Portugal, Universidade Sorbonne-Paris, a Associação Latinoamericana de Sociologia - ALAS, a CPLP, o Instituto Camões, o INCOM, alguns Museus de antropologia, a exemplo do Quai Branly - França, o TRAIN-Universidades como a de Londres, e instituições africanas, em especial a de países de língua portuguesa, seja pelo seu caráter estratégico, seja pelas relações pré-existentes com a Fundaj, ainda que frágeis.

As cooperações articuladas deverão ser orientadas por um plano, elaborado a partir da identificação dos interesses comuns e com base nas expertises institucionais. Além disso, as instituições envolvidas deverão buscar conjuntamente meios de financiamentos nos governos de seus países e/ou em organismos internacionais de fomento.

Neste contexto, uma parceria Fundação Joaquim Nabuco e Cuba é muito bem vinda e encontra respaldo nas diretrizes governamentais. Avançar nesse aspecto é mais que urgente, principalmente pelo conhecimento já adquirido pelos pesquisadores cubanos, que estiveram recentemente na Fundação e poderão conhecer suas áreas de atuação. 
Assim, o programa de cooperação internacional proposto estrutura-se em três eixos de ação, voltados para promover a colaboração científica e cultural entre a Fundaj e instituições estrangeiras, em especial as latino-americanas e africanas, com o objetivo de apoiar a implementação de iniciativas em favor do desenvolvimento das regiões em que atuam e por demanda delas:

1. Formação;

2. Desenvolvimento de Pesquisa Institucional;

3. Disseminação de Conhecimento (eventos, publicações e outras mídias).

Para consecução dos eixos orientadores do Programa, sugere-se um conjunto de metas e estratégias a serem alcançados por meio de acordos bilaterais diretos ou intermediados pelos Ministérios da educação, das Relações Exteriores, Meio Ambiente, Cultura e Ciência e Tecnologia.

No eixo da Formação o desenvolvimento de atividades de pós-graduação para formação de talentos do nordeste brasileiro (inclusive servidores da Fundação) e dos países latino americanos e africanos de língua portuguesa no contexto mundial, buscando a excelência nas áreas de gestão educacional, de formulação de políticas públicas, restauração e de arte contemporânea. No eixo do Desenvolvimento de Pesquisa Institucional a colaboração em pesquisas de instituições afins e desenvolvimento de diagnósticos e programas conjuntos de pesquisa, envolvendo brasileiros e estrangeiros, especialmente da América Latina e África com enfoque nas políticas públicas dos países em desenvolvimento. Por fim no eixo da Disseminação do Conhecimento e boas práticas produzidas na Fundação e/ou em instituições estrangeiras no campo da gestão educacional e cultural, da formulação e implementação de políticas públicas, por meio da realização seminários, debates e exposições resultantes do intercâmbio de experiências.

Para garantir a efetividade do plano de cooperação internacional da Fundaj será necessária a adoção de algumas medidas, elencadas abaixo:

- Estudo e flexibilzação das normas que regem as relações internacionais em parceria com a Procuradoria Jurídica da instituição e apoio do MRE, por meio do Escritório de Representação para o Norte e Nordeste-ETENE;

- Investimento na capacitação dos servidores em idiomas estrangeiros, com prioridade para o inglês, espanhol e francês;

- Incentivo as articulações individuais que se revertam em projetos institucionais;

- Implementação de uma política de financiamento da participação de servidores em eventos internacionais, condicionada ao compromisso de devolução 
para instituição (relatórios, artigos e articulações com instituições locais e disseminação interna), considerando cada servidor um articulador em potencial;

- Inserção da Fundaj nas redes de instituições de pesquisa, formação e cultura;

- Elaboração de acordos de cooperação de caráter mais abrangente.

As perspectivas de uma significativa ampliação da cooperação internacional da Fundação Joaquim Nabuco é uma diretriz estratégica da instituição, que pode contribuir efetivamente com o mundo, principalmente com as Américas e mais especificamente ainda, com Cuba, por meio de trocas, certamente exitosas de conhecimentos na pesquisa, formação e divulgação científica e difusão cultural.

Recife, Olinda, Maceió, 2013 